\title{
ALT Text and Basic Accessibility
}

\author{
Tom McEwan \\ Napier University, Edinburgh. \\ 10 Colinton Road, \\ Edinburgh EH11 1PN, UK \\ +441314552793 \\ t.mcewan@napier.ac.uk
}

\begin{abstract}
Recent surveys have shown that the majority of websites are not accessible. Despite legal obligations and the importance of the internet for disabled people, most websites fail to reach a basic level of accessibility, yet web developers are not short of accessibility guidelines and recommendations. This preliminary study consists of a meta-review of web accessibility studies in order to identify a set of common barriers faced by the impaired. Automated testing, of websites created by recent multimedia graduates in their final semester, confirms these problems. In particular non-use, and incorrect use, of ALT (alternative) text emerges as the most frequent, basic error. We conclude that ALT is a litmus test of developers' attitudes towards accessibility and propose future work to identify how to understand and improve these attitudes
\end{abstract}

\section{Categories and Subject Descriptors \\ H.5.4 Hypertext/Hypermedia. I.7.2 HTML}

\section{General Terms}

Human Factors, Standardization, Legal Aspects.

\section{Keywords}

Web Development, accessibility compliance

\section{INTRODUCTION}

Despite standards (e.g. W3C standards), guidelines (e.g. Web Content Accessibility Guidelines) and laws (e.g. [1]) designed to ensure that all websites are accessible to all users, recent surveys (eg [7]) find that more than $80 \%$ of websites have accessibility problems. Ignorance alone does not explain this it seems that accessibility is simply not a priority for (increasingly professionalised) web developers. The objective of this initial study is to identify the common reported accessibility problems, and to confirm whether they are present in the portfolios of new entrants to the profession. This will lead to future work with practitioners that will investigate why these standards, guidelines and laws do not lead to improvements in web development practice and to identify how to address this situation.

\subsection{Web Accessibility}

For those with access, the growth of the web has given us access to a multitude of services and information sources:

(C) T.McEwan, B. Weerts, 2007

Published by the British Computer Society

Volume 2 Proceedings of the 21st BCS HCI Group Conference

HCI 2007, 3-7 September 2007, Lancaster University, UK Devina Ramduny-Ellis \& Dorothy Rachovides (Editors)

\author{
Ben Weerts \\ Napier University, Edinburgh. \\ 10 Colinton Road, \\ Edinburgh EH11 1PN, UK \\ +441314552793

\section{benweerts@hotmail.com}

online banking, online shopping, vacation and travel planning, and instant messaging. These services make it possible for most people to do their daily activities online and without having to leave the house. For many the internet has become an indispensable and integral part of their daily lives [10]. For people with impairments, there are now many more options to access information and services than in the past. The visually impaired can listen to online newspapers and magazines, the physically impaired can shop online for goods even if they are unable to access existing shops, and so on. Many services and activities that were impossible or hard to do before for people with impairments can now be done online via assistive technologies (screen readers, voice browsers, alternative keyboards, speech recognition, etc) [24]. All of this, of course, assumes that website creators do not erect accessibility barriers that exclude categories of impaired users.

\subsection{Legal Requirements}

Many countries now have relevant legislation, though typically this is part of some general disability or equality legislation and not specific to web accessibility [21]. For example, part III of the UK Disability Discrimination Act 1995 (DDA) [1] requires providers of goods, facilities and services to avoid treating those with impairments "less favourably" than others, and to make "reasonable adjustments" to ensure access information and services (including websites). However, the DDA does not clearly state how accessibility should be achieved, and the term "reasonable adjustments" is vague and can lead to confusion. In the USA, the 1998 amendment [22] to Section 508 of the Rehabilitation Act establishes requirements for accessible websites for federal departments and agencies, to ensure that the disabled have the same access to, and use of, information as others. The EU's "eAccessibility" [9] encourages member states to use a "design for all" approach, to remove all barriers to accessing information and communication technologies (ICT), advocating compliance through accessibility certification. Some claim the majority of UK websites contravene the DDA [20], and, although there has, as yet, been no UK legal decision, in Australia, Maguire successfully sued the Sydney Organising Committee for the Olympic Games [3]. Given the global nature of the internet, however, it will be difficult to enforce some accessibility laws across national boundaries.

\subsection{Accessibility in Practice}

Despite the importance of the net for disabled people and the legal requirements, recent research $[\mathrm{eg} 7,14,16]$ reveals that the majority of websites are still not accessible. $81 \%$ of 1000 websites tested in 2004 [7] had accessibility failings, and tests with disabled users revealed that it is impossible for people with certain impairments to make use of the services provided. $94 \%$ of 200 Irish websites, across various sectors and service types, were found to be inaccessible [16]. A follow up study [21] found hope for improvement: the majority of the tested websites may still be inaccessible, but web developers are increasingly aware of accessibility issues). $95 \%$ of 162 British university homepages 
are inaccessible [13]. American studies [18, 20] of higher education websites suggest a partial improvement - websites are not completely inaccessible $(40 \%$ achieve at least basic levels of accessibility), but are still far from fully accessible. We can conclude that the majority of the tested websites are not accessible, and two common problems emerge: disabled users find it difficult to use the provided online services, and, web developers are not sufficiently aware of, or do not prioritise, accessibility. The first viewpoint is clearly widely held. $93 \%$ of the blind users have difficulties using search engines [2]; on average, disabled people can only perform $76 \%$ of the tasks on websites [7]. The second viewpoint, however, seems to receive less analysis, so this study therefore will investigate why developers seem unaware of, or don't care about, the accessibility barriers they erect.

\section{Meta-review}

The current Web Content Accessibility Guidelines version 1.0 [27] (WCAG 1.0 - a second version, WCAG 2.0 [28] is not yet completed) provides 14 guidelines, each with one or more checkpoints, and split into 3 levels of priority. There are also 3 levels of conformance with the guidelines: levels A, AA and AAA, describing cumulative adherence to priorities $1,1 \& 2$, $1 \& 2 \& 3$ respectively.

We analysed 10 accessibility studies for the most frequently recurring accessibility errors. There are several ways of evaluating websites for compliance with WCAG1.0. At a very basic level an automatic software tool can be used to test for compliance, though use of these tools alone does not guarantee accessibility [16] and the tools' users need to have a good understanding of WCAG and how the tool works [6]. Not all guidelines can be fully checked automatically for conformance, and a human expert has to test certain guidelines for compliance [16]. A combination of automatic and manual checking is required because manual testers might miss some errors that automatic tools would have found [21]. Improved measurement of accessibility can be achieved by including user simulation to help understand how the user interacts with the website, though it is very difficult for a non-disabled person to have the same experience as a disabled person. User evaluation is thought to give the best indication of accessibility - by getting experts and disabled users to give an in-depth evaluation of the website [21].

Each study had used WCAG 1.0 and one [14] also used Section 508 guidelines. All but one [11] used automated testing with Bobby (now called WebXact [23]) as their preferred testing tool. Some studies also used manual testing, user evaluation and/or simulation. Size varies from thirty [4] to one thousand [7] websites. We examined each study for three most frequently recurring accessibility errors they report, and these are listed in Table 1, which also presents details about each survey. In collating the most frequent accessibility errors, we disregarded the size of studies, since there was insufficient data to normalize them. The most common accessibility problems are, in order of frequency: No alternative (ALT) text for non-text elements; No titles for frames; Use of absolute sizing and positioning.

\begin{tabular}{|c|c|c|c|c|c|}
\hline Title & $\begin{array}{l}\text { Eval'n } \\
\text { Method } \\
\end{array}$ & Size & Most Common Barrier & $2^{\text {nd }}$ Most Common & $3^{\text {rd }}$ Most Common \\
\hline $\begin{array}{l}\text { Evaluation of consumer health website } \\
\text { accessibility by users with sensory and } \\
\text { physical disabilities [4] }\end{array}$ & $\begin{array}{l}\text { Auto \& } \\
\text { manual }\end{array}$ & 30 & $\begin{array}{l}\text { Provide ALT text for all } \\
\text { images }\end{array}$ & $\begin{array}{l}\text { If an image conveys important } \\
\text { information beyond its ALT text, } \\
\text { provide extended description. }\end{array}$ & $\begin{array}{l}\text { Provide ALT content for each } \\
\text { SCRIPT that conveys important } \\
\text { information or functionality }\end{array}$ \\
\hline $\begin{array}{l}\text { The Web - Access and Inclusion for } \\
\text { Disabled People [7] }\end{array}$ & $\begin{array}{l}\text { Auto, } \\
\text { manual, user } \\
\text { simulation }\end{array}$ & 1000 & $\begin{array}{l}\text { Provide a text equivalent } \\
\text { for every non-text element }\end{array}$ & $\begin{array}{l}\text { Ensure that foreground and } \\
\text { background colours provide } \\
\text { sufficient contrast }\end{array}$ & $\begin{array}{l}\text { Ensure that pages are usable } \\
\text { when scripts, }(\ldots) \text { are turned } \\
\text { off or not supported }\end{array}$ \\
\hline $\begin{array}{l}\text { A Review of Selected E-Recruiting } \\
\text { Websites - Disability Accessibility } \\
\text { Considerations [8] }\end{array}$ & $\begin{array}{l}\text { Auto \& User } \\
\text { Simulation }\end{array}$ & 41 & $\begin{array}{l}\text { Provide ALT text for all } \\
\text { images }\end{array}$ & $\begin{array}{l}\text { Provide ALT text for all image- } \\
\text { type buttons in forms }\end{array}$ & $\begin{array}{l}\text { Provide ALT text for all image } \\
\text { map ... (AREAs) }\end{array}$ \\
\hline $\begin{array}{l}\text { Usability of E-Government Web-Sites } \\
\text { for People with Disabilities [11] }\end{array}$ & Manual & 35 & $\begin{array}{l}\text { Provide a text equivalent } \\
\text { for every non-text element }\end{array}$ & $\begin{array}{l}\text { Organize documents so they may } \\
\text { be read without style sheets }\end{array}$ & $\begin{array}{l}\text { Identify row and column } \\
\text { headers for data tables }\end{array}$ \\
\hline $\begin{array}{l}\text { Web site accessibility: a study of six } \\
\text { genres [12] }\end{array}$ & Auto & 549 & $\begin{array}{l}\text { Provide ALT text for all } \\
\text { images }\end{array}$ & Provide a title for each frame & $\begin{array}{l}\text { Provide ALT text for all image } \\
\text { map ... (AREAs) }\end{array}$ \\
\hline $\begin{array}{l}\text { Web Accessibility in the Mid-Atlantic } \\
\text { United States: A Study of } 50 \text { Home } \\
\text { Pages [14] }\end{array}$ & $\begin{array}{l}\text { Auto \& } \\
\text { manual }\end{array}$ & 50 & $\begin{array}{l}\text { Provide ALT text for all } \\
\text { images }\end{array}$ & $\begin{array}{l}\text { Ensure pages are usable when } \\
\text { scripts, (...) are turned off or not } \\
\text { supported }\end{array}$ & $\begin{array}{l}\text { Ensure that all information } \\
\text { conveyed with color is also } \\
\text { available without color }\end{array}$ \\
\hline $\begin{array}{l}\text { Web site accessibility: an online sector } \\
\text { analysis [15] }\end{array}$ & Auto & 45 & $\begin{array}{l}\text { Use relative sizing and } \\
\text { positioning }\end{array}$ & Identify the language of the text & Provide a summary for tables \\
\hline $\begin{array}{l}\text { WARP - Web Accessibility - Reporting } \\
\text { Project - Ireland } 2002 \text { [16] }\end{array}$ & Auto & $\sim 200$ & $\begin{array}{l}\text { Use of relative sizing \& } \\
\text { positioning }\end{array}$ & Provide ALT text for all images & $\begin{array}{l}\text { Use a public text identifier in a } \\
\text { DOCTYPE statement }\end{array}$ \\
\hline $\begin{array}{l}\text { The Accessibility of Web Pages for Mid- } \\
\text { Sized College \& Univ. Libraries [18] }\end{array}$ & Auto & 190 & $\begin{array}{l}\text { Provide ALT text for all } \\
\text { images }\end{array}$ & $\begin{array}{l}\text { Provide ALT text for all image } \\
\text { map hot-spots (AREAs) }\end{array}$ & Provide a title for each frame \\
\hline $\begin{array}{l}\text { An assessment of Web accessibility of } \\
\text { UK accountancy firms [26] }\end{array}$ & Auto & 72 & $\begin{array}{l}\text { Provide ALT text for all } \\
\text { images }\end{array}$ & Provide a title for each frame & $\begin{array}{l}\text { Provide ALT text for all image } \\
\text { map hot-spots (AREAs) }\end{array}$ \\
\hline
\end{tabular}

Table 1: Review of Web Accessibility Studies

\subsection{ALT text}

Eight of the studies report the ALT text problem as the most frequent, and only one does not list it in the top three. There are many non-text elements which are only accessible to some users [19] through the ALT text: images, image map hot-spots, audio, video, graphical buttons, applets, animations, but images were reported to cause the most problems. The guidelines [27] state that a text equivalent must be provided and fulfil the same function for a disabled person as it does for a person without a disability. This ensures that users relying on assistive technology, such as screen readers, can access the same information as others. If ALT text is absent, the screen reader cannot provide that access - it will either simply not inform the user of that image or it will convey other information (e.g. filename) [25].

There are admittedly a number of perspectives on ALT text poor descriptions can be considered worse than none at all, and text should be succinct and accurate. If nothing else, however, something as simple to implement (and test for) as ALT does indicate the willingness of the developer to take accessibility into 
account. When determining appropriate alternative text for images, the purpose of the image should be considered first. Images can be used for a variety of purposes and each image type should use ALT text in a different way. One study [5] classifies five different categories of image (layout, decoration, navigation, supplement and content), with different ALT text suggestions for each, and the draft guidelines [28] makes similar recommendations. The same image will require different ALT text according to the reason for, and location of, its use. ALT text should be generated case by case and the diverse needs and capabilities of disabled users should be considered [16]. ALT text should also be kept as accurate and succinct possible. Unnecessarily long ALT text makes it more difficult for users of assistive technology to understand the website content $[25,26]$.

\subsection{Other accessibility barriers}

There are other common accessibility barriers found in these studies. Several $[16,18,26]$ report "frame problems", in particular, frames without titles. Frames make it possible to display more than one web page in the same browser window, but are particularly problematic for the visually impaired, especially if frames are not meaningfully titled. The use of absolute sizing and positioning is another frequently recurring accessibility barrier $[15,16]$. The size and position of HTML elements (text size, column widths, etc.) can be specified in relative units and then scaled according to the user's preferences for the browser. This is particularly useful for users with limited vision using standard browsing technology [16].

Other, less frequent accessibility barriers are reported in the above accessibility studies, although it is possible that their less frequent recurrence is due to the methodologies of the studies involved. Additionally a limitation of our approach is our focus on frequency rather than seriousness of these barriers. It is possible that certain common problems have little impact and are relatively easy to solve, while other less frequent problems can have a more serious impact.

\section{Trainee Web Developers}

We had access to an opportunistic sample - the websites produced by 40 final year undergraduates as an assessment for a Multimedia Technology module. By the time of our study, most of these students had graduated and either had, or were seeking, jobs as web developers, and kept their websites publicly available as an online portfolio. For the assessment they had to develop a publicly available website that contains an introduction screen, a menu, information on an e-learning application and the application itself. The students were asked to follow accessibility guidelines when designing the website, but accessibility itself is neither a module learning outcome nor a significant factor in the marks. All students had previously passed a Web Development module which required them to demonstrate basic understanding of web accessibility, and other HCI-related modules.

As final year students they are the web developers of the future - "destinations surveys" suggest most enter the web development industry after their course, mainly as developers. We hoped that their conformance to (at least) level A in WCAG 1.0 would be a good indication of the extent to which their previous learning remained with them and would inform future practice. The results were surprising and disappointing. Although it is possible that some took a strategic approach to assessment and deliberately ignored the guidelines, it would appear that most had not retained their earlier learning.
Given that some time had elapsed since the assessment was completed, not all sites were still publicly available. In total 30 websites were successfully evaluated for accessibility, using the same approach as others $[12,26]$ take, recording: WebXact approval or not; Priority 1 errors; and reported user checks. No manual checks were performed. 9 gained level A conformance, 2 gained level AA, 2 gained level AAA. The majority did not conform: 16 failed to meet any of the Priority Guidelines, 1 met Priority 2 but not Priority 1 . Table 2 contains the priority 1 issues, the most basic level of accessibility. Almost all are ALT text-related. Given that only 4 students did better than level A conformance, Priority 2 and 3 issues were even more prevalent.

Table 2: Accessibility Error Frequency in Student Sites

\begin{tabular}{|l|l|l|l|}
\hline & Explanation & sites & \\
\hline 1.1 & Provide a text equivalent for images & 12 & P1 \\
\hline 1.1 & Provide a text equivalent for objects & 10 & P1 \\
\hline 1.1 & Provide a text equivalent for ASCII art & 2 & P1 \\
\hline 12.1 & $\begin{array}{l}\text { Title each frame to facilitate frame } \\
\text { identification and navigation }\end{array}$ & 2 & P1 \\
\hline 6.2 & $\begin{array}{l}\text { Update equivalents for dynamic } \\
\text { content when the dynamic content } \\
\text { changes }\end{array}$ & 1 & P1 \\
\hline
\end{tabular}

\subsection{Limitations and Future Work}

Although there is correlation between our future web developers practices and past studies into web accessibility, this could be in part due to our using the same automated testing method as used in most of the studies. WebXact is useful, but it has several limitations. It can only test for a certain number of WCAG 1.0 checkpoints and users must test the remaining checkpoints manually. It can't test the accessibility of scripts, cascading style sheets and secure websites. It occasionally reports false positive or false negative results [17, p42]. It also shows some difficulties with distinguishing between the impact of different appearances of the same type of error. But despite its limitations, WebXact has been the preferred accessibility tool of many accessibility studies [eg 8, 12, 13, 15, 16, 26], and using it here allows us to make comparisons with other studies. Also, our accessibility testing is limited to testing the homepage only, though this gateway is considered $[14$, p.7, 26] to be a good indicator of the overall accessibility of a website. If the homepage is not accessible then it will be difficult for a person with an impairment to access the rest of the website.

Accessibility is clearly a fundamental competency required by a web developer. In the British Computing Society's SFIAplus competency framework, the "Website Specialist" role definition includes (Ref: TSWBSP302) "Is aware of the special requirements of the visually impaired and hard of hearing". In the next stage of our study we will explore such statements in interviews with professional web developers from a variety of companies. We hope to establish their level of understanding of, and sympathy towards, accessibility, and then to analyse their work processes for how, when, why and by whom, ALT text is written. We also want to identify whether customers prioritise accessibility, or even ask for it. We hope to identify when accessibility is tested/evaluated and by whom and when, and whether users with impairments are included as testers. We then plan to evaluate the usefulness of guidelines, and in particular WCAG 2.0, in order to suggest improvements to tools, training, working practices and competency definitions. 


\section{Conclusions}

Repeated studies have shown that ALT text is the most fundamental accessibility problem in commercial website development. There may be other issues that have a greater impact on different groups of users, in different contexts, but despite (or perhaps because of) a variety of guidelines, this most basic form of accessibility compliance is achieved in a minority of websites.

While ALT text is not a panacea for accessibility, it may be a bell-weather for the developer's commitment to accessibility. It is the most frequently recurring failure to follow the most basic accessibility guidelines. As such it is often taught relatively early in university degree courses, yet this knowledge does not seem to stay with students as they move into practice. For the social inclusion of people with impairments, to ensure that university courses are fit for purpose, and for the professionalism of web development, it is vital to understand why ALT text remains problematic, and then provide redress.

\section{REFERENCES}

[1] British Government (1997). Disability Discrimination Act 1995 (c. 50). Retrieved June 14, 2006 from http://www.opsi.gov.uk/acts/acts1995/1995050.htm.

[2] Buzzi, M., Andronico, P. \& Leporini, B. (2004) Accessibility and Usability of Search Engine Interfaces: Preliminary Testing. Retrieved July 8, 2006 from http://ui4all.ics.forth.gr/workshop2004/files/ui4all_proceedi ngs /adjunct/accessibility/58.pdf.

[3] Carter, W. (2000). Bruce Lindsay Maguire v Sydney Organising Committee for the Olympic Games. Retrieved July 5, 2006 from http://www.humanrights.gov.au/disability_rights/decisions/c omdec/2000/DD000120.htm.

[4] Chiang, M.F., \& Starren, J. (2004). Evaluation of consumer health website accessibility by users with sensory and physical disabilities. Proceedings of Medinfo 2004; IOS Press, Amsterdam, 2004:1128-1132.

[5] Danino, N. \& MacFarlane, S. (2001). Images on the Web: A suitable alternative. In J. Vanderdonckt, A. Blandford \& A. Derycke (Eds.), Interaction without frontiers, Volume II. 109-112. Toulouse: Cépaduès-Ėditions.

[6] Diaper, D. \& Worman, L. (2003) Two Falls out of Three in the Automated Accessibility Assessment of World Wide Web Sites: A-Prompt v. Bobby. In P. Johnson. \& P. Palanque (Eds.) People and Computers XVII. SpringerVerlag.

[7] Disability Rights Commission (DRC). (2004). The Web: Access and Inclusion for Disabled People. London: TSO.

[8] Erickson, W. \& Bruyère, S. (2002) A Review of Selected E-Recruiting Websites: Disability Accessibility Considerations. Cornell University.

[9] European Commission. (2006). eAccessibility. Retrieved July 8, 2006 from http://europa.eu/scadplus/leg/en/lvb/124226h.htm.

[10] Hoffman, D., Novak, T., \& Peralta, M. (2004). Has the Internet become indispensable? Communications of the ACM, 40(2), 37-42.

[11] Huang, C. (2002). Usability of E-Government Web-Sites for People with Disabilities \& Accessibility of E-
Government Web-Sites in Taiwan. Proceedings of the Annual Hawaii International Conference on System Sciences, USA, 36, p147c.

[12] Jackson-Sanborn, E., Odess-Harnish, K., \& Warren, N. (2002). Web site accessibility: a study of six genres. Library Hi-Tech, 20(3), 308-317.

[13] Kelly, B. (2002). An Accessibility Analysis Of UK University Entry Points. Retrieved June 29, 2006 from http://www.ariadne.ac.uk/issue33/web-watch/.

[14] Lazar, J., \& et al. (2003). Web Accessibility in the MidAtlantic United States: A Study of 50 Home Pages. Universal Access in the Information Society Journal, 2(4), 331-341.

[15] Loiacono, E., \& McCoy, S. (2004). Web site accessibility: an online sector analysis. Information Technology \& People, 17(1), 87-101.

[16] McMullin, B. (2002). WARP: Web Accessibility Reporting Project Ireland 2002 Baseline Study. Retrieved June 11, 2006 from http://eaccess.rince.ie/white-papers/2002/warp2002-00/warp-2002-00.pdf.

[17] Schmetzke, A. (2001). Web accessibility at university libraries and library schools. Library Hi Tech, 19(1), 35-49.

[18] Spindler, T. (2004). The Accessibility of Web Pages for Mid-Sized College and University Libraries. Reference \& User Services Quarterly, 42(2), 149-154.

[19] Thatcher, J. et al. (2002). Constructing accessible web sites. Birmingham: Glasshaus.

[20] Thompson, T., Burgstahler, S. \& Comden, D. (2003) Research on Web Accessibility in Higher Education. Retrieved July 7, 2006 from http://www.rit.edu/ easi/itd/itdv09n2/thompson.htm.

[21] Trulock, V. (2006). A comparative investigation of the accessibility levels of Irish websites. Unpublished MSc dissertation. Edinburgh, UK: Napier University.

[22] US Government. (1998, August). Amendment to Section 508 of the Rehabilitation Act. Retrieved July 4, 2006 from http://www.section508.gov/index.cfm?FuseAction=Content\& $\underline{\mathrm{ID}=14}$.

[23] Watchfire WebXact. (n.d.). Retrieved March 31, 2007 from http://www.webxact.com/.

[24] Web Accessibility in Mind (WebAIM). (n.d.(a)). Introduction to Web Accessibility. Retrieved July 6, 2006 from http://www.webaim.org/intro/.

[25] WebAIM. (n.d.(b)). Creating Accessible Images. Retrieved July 10, 2006 from http://www.webaim.org/techniques/images/alt text.php.

[26] Williams, R. \& Rattray, R. (2003). An assessment of web accessibility of UK accountancy firms. Managerial Auditing Journal, 9(16), 710-716.

[27] World Wide Web Consortium (W3C). (1999a). Web Content Accessibility Guidelines 1.0. Retrieved June 14, 2006 from http://www.w3.org/TR/WCAG10.

[28] W3C. (2006a). Web Content Accessibility Guidelines 2.0. Retrieved September 21, 2006 from http://www.w3.org/TR/WCAG20/Overview.html\#contents. 